\title{
Cognitive Styles and Performance on Schema- based Cloze Multiple Choice Item Tests: A Fairness Issue
}

\author{
Ebrahim Khodadady \\ Ferdowsi University of Mashhad, Iran \\ Email: ekhodadady@ferdowsi.um.ac.ir \\ Azar Hosseini Fatemi \\ Ferdowsi University of Mashhad, Iran \\ Saba Etminan \\ Ferdowsi University of Mashhad, Iran
}

\begin{abstract}
This study reports the performance of 253 undergraduate and graduate students of English on the Group Embedded Figures Test (GEFT) and a schema-based cloze multiple choice item test (SBCMCIT) and its subtests as measures of cognitive styles and English language proficiency, respectively. Although field independent (FI) test takers outperformed their field dependent (FD) counterparts on the SBCMCIT, their performance showed relatively weaker and unexpectedly negative relationships with the GEFT. Assigning the participants to low, middle, and high proficiency groups on the basis of their standardized scores on the SBCMCIT and correlating them with the GEFT, however, showed that neither low nor high proficiency groups employed their cognitive styles because their performance on the two tests did not reveal any significant correlations. The middle proficiency group, however, employed both FD and FI cognitive styles to compensate for their partially acquired language proficiency and thus their scores on the SBCMCIT and two of its subtests showed significant correlations with the GEFT. The results are discussed in terms of cognitive styles and fairness in language testing.
\end{abstract}

Index Terms - cognitive styles, field dependency, field independency, schema theory, fairness

\section{INTRODUCTION}

The study of cognitive styles started late in the $19^{\text {th }}$ century when some scholars noticed that learners adopt different approaches towards understanding a single phenomenon (Dornyei, 2005). This observation resulted in the identification of a number of cognitive styles particularly at the beginning of $20^{\text {th }}$ century. After reviewing the literature Keefe (1979) declared that a given cognitive style is adopted when a link is established between personality and cognition and thus related it to learning in general and adopting a particular approach towards solving problems in particular.

Goldstein and Blackman (1978) gave cognitive styles an explanatory power by viewing them as hypothetical constructs which are, according to Hayes and Allinson (1998), related to the manner in which people interact with their environment, organize and interpret what they understand from the interaction and employ their interpretations to take appropriate actions. As constructs, cognitive styles not only influence learning from interactions but also play an important role in the way learners function in the society psychologically and socially (Kahtz \& Kling, 1999).

Jarvis (2005) provided an exhaustive list of cognitive styles which can be consulted for further study. Table 1, however, summarizes the literature on cognitive styles by relating them to particular manners in which scholars have treated the same cognitive styles. They believe the adoption a certain style determines the possible effect of individual differences on learning. As can be seen, the differences are basically dichotomies in nature and depend on the approach a given researcher adopts in describing the cognitive styles, e.g., perceptual Witkin (1974) or logical (Hudson, 1966). 
TABLE 1

THE DICHOTOMOUS CATEGORIZATION OF COGNITIVE STYLES

\begin{tabular}{|l|l|l|}
\hline Reference & Styles & Description \\
\hline \multirow{2}{*}{$\begin{array}{l}\text { Witkin \& Goodenough } \\
(1981)\end{array}$} & Field dependent & Perception of an object or situation is altered by its context \\
\cline { 2 - 3 } Hudson (1966) & Field independent & Perception is more independent of its context \\
\hline \multirow{2}{*}{ Pask (1976, 1988) } & Converger & Logical deductive approach to problem-solving \\
\cline { 2 - 3 } & Diverger & Intuitive and imaginative image to problems \\
\hline \multirow{2}{*}{$\begin{array}{l}\text { Gregorc, 1982; Allinson \& } \\
\text { Hayes }(1966)\end{array}$} & Serialist & Working through a task one piece at a time \\
\cline { 2 - 3 } & Wholist & Viewing a task or situation as a whole \\
\cline { 2 - 3 } Paivio $(1971,1986)$ & Reflective & Learns thorough experience \\
\cline { 2 - 3 } & Verbaliser & Learns thorough reflection \\
\cline { 2 - 3 } & Visualiser & Information is most easily processed in verbal form \\
\hline
\end{tabular}

Among the categorizations specified in Table 1, field dependent (FD) and field independent (FI) cognitive styles have gained wider popularity particularly because they are measured by a non-linguistic test called the Group Embedded Figures Test (GEFT). (It will be described in some details in the instrumentation section.) SalmaniNodoushan (2007), for example, administered the GEFT along with the 1990 version of the IELTS to 1743 freshman, sophomore, junior, and senior students of English at various universities and colleges in Iran. His results showed that "FD participants outperformed their FI counterparts on true-false, outlining, and elicitation tasks; on the contrary, FI participants outperformed FD participants on sentence-completion and scanning tasks" (p. 103).

In order to explain his findings, Salmani-Nodoushan (2007) opined that the difference in the performance of FD and FI participants might be attributed to the nature of tasks. In other words, tasks such as true-false questions require a cognitive style different from other tasks such as completing sentences. If this argument holds true, then employing language tests which employ certain type of questions such as multiple choice items would not be fair because they might favour the test takers whose cognitive styles are compatible with the nature of questions.

Schema-based cloze multiple choice item tests (SBCMCITs) are, for example, one of the most recently developed measures of achievement as well as proficiency which are confirmed to be superior to their traditional counterparts because of their strong theoretical foundation (Khodadady, 1997, 1999a; Khodadady \& Herriman 2000). Instead of being based on the intuition of test designers, the writers of SBCMCITs view each and all words/phrases comprising texts as schemata and divide them into three main domains, i.e., semantic, syntactic and parasyntactic.

The semantic domain of schemata consists of four genera which carry the message expressed in the text, i.e., adjectives, adverbs, nouns and verbs. Similarly, each semantic genus comprises species which contain their own types. The adjective genus of semantic domain is, for example, subsumed by agentive, complex, comparative, dative, derivational, nominal, simple, and superlative species. The agentive species of adjective genus forming a text may, for example, consist of types such as fascinating and encouraging.

While semantic schemata are many in type but few in frequency, the syntactic schemata are few in types but many in frequency. As the first genus of syntactic domain, conjunctions, for example, consist of just two species, i.e., phrasal and simple. The simple conjunction species of syntactic domain contribute schemata such as and and or to the formation of given texts. Similarly, determiners, prepositions, pronouns, and syntactic verbs consist of species whose types are few but frequently employed to connect the semantic schemata together cohesively and coherently. Khodadady's (2008) findings, for example, showed that only twelve types of syntactic verbs had been employed in the entire textbook called Reading Media Texts: Iran-America Relations (Khodadady, 1999b).

The parasyntactic domain of schemata consist of seven genera, i.e., abbreviations, interjections, names, numerals, para-adverbs, particles, and symbols whose type and frequency might be many, however, they have the same function as the syntactic schemata. For example, as many as 343 different names had been used in Reading Media Texts: IranAmerica Relations (Khodadady, 1999b). In spite of being many in types, names are similar to pronouns in that the reader must know who they refer to in order to understand what is expressed in relation to presidents such as Bush and Khatami.

Based on the distinctions made regarding schema domains, Gholami (2006) designed a study to find out whether developing a SBCMCIT on each and all of the four semantic genera, i.e., adjectives, adverbs, nouns and verbs, will bring about any significant differences in the performance of test takers. To fulfill the objective, she administered the disclosed TOEFL to 92 undergraduate students majoring in English in two universities in Mashhad and employed their total scores on the TOEFL to establish five groups of test takers being homogeneous in their language proficiency. Then she developed 60 items on each of the four semantic genera comprising the authentic and unmodified text "why don't we just kiss and make up" (Dugatkin, 2005) and thus came up with a SBCMCIT in four versions. Gholami also developed a fifth version on the semantic domain which included a proportionately balanced number of all the semantic genera comprising the text and then administered the tests to the five homogenous groups. (The results will be presented in the Instrumentation section shortly.) In the present study the fifth version developed on the semantic domain was employed to explore whether there is any significant relationship between cognitive styles and performance on the SBCMICT. 


\section{METHOD}

\section{A. Participants}

Two hundred fifty three undergraduate and graduate students majoring in Teaching English as a Foreign Language, English Language and Literature, and English Translation at Ferdowsi University of Mashhad, Imam Reza University, Khayyam University, Mashhad Azad University, and Tehran University along with one hundred twenty seven students of FCE and CAE1 at Aryanpour College participated in the study voluntarily. The latter were studying agriculture, architecture, chemistry, dentistry, engineering, geology, management, medicine, nursing, Persian literature, pharmacy, and physics at various universities. One hundred and forty one $(55.7 \%)$ were female and $112(44.3 \%)$ were male whose age ranged from 18 to 53 (Mean $=24.52, \mathrm{SD}=4.470)$. All the participants spoke Persian as their mother language.

\section{B. Instruments}

Two instruments were employed in this study:

Group Embedded Figure Test

Witkin, Oltman, Raskin, and Karp (1971) developed the group embedded figure test (GEFT) and reported the reliability coefficient of 0.82 for the test. It comprises three sections with 25 complex figures from which participants identify eight sample forms. While section one of the GEFT includes seven figures mainly designed to warm up the test takers, sections two and three include nine complex figures each. The participants' are provided with sample form labeled $\mathrm{A}$ to $\mathrm{H}$ and required to locate them within the 25 complex figures by tracing the given forms over the lines of the complex figures in the same direction, size and proportion with a pencil. The complex figure is considered the dominant visual field and a given test taker's ability to identify the labeled sample form within the complex figures measures if $s /$ he is dominated by the visual field or not. The first seven questions are treated as practice items and the remaining 18 questions are scored to determine the test takers' cognitive style. The total possible score on the GEFT is, therefore, 18 with a mean of 11 . The test takers achieving a GEFT score below and above the mean are labeled FD and FI, respectively (e.g., Luk, 1998). Figure 1 provides a sample GEFT item requiring test-takers trace figure G in a complex figure.
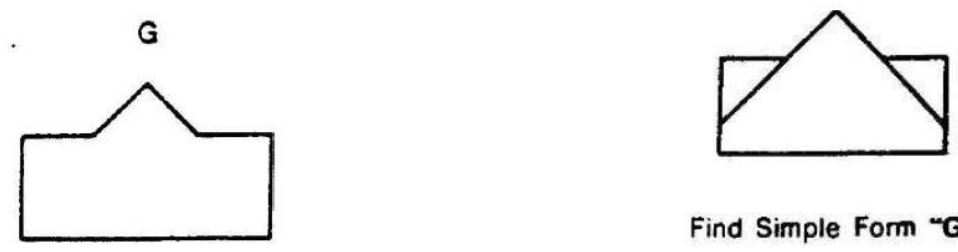

Figure 1. An example GEFT item requiring tracing a given figure

\section{Semantic Domain Schema-Based Cloze Multiple Choice Item Test}

Gholami (2006) developed four versions of a close multiple choice item test (CMCIT) on 60 adjectives, 60 adverbs, 60 nouns and 60 verbs comprising the authentic and unmodified text "why don't we just kiss and make up" (Dugatkin, 2005). Since the three choices comprising the CMCIT had semantic and syntactic relations with the keyed response and their selection depended on understanding the keyed response within the context of the passage, she called them schema-based CMCITs (SBCMCITs). She also developed a fifth test called semantic domain SBCMCIT in her study. It consists of 14 adjectives, seven adverbs, 24 nouns and 15 verbs of the same text. When she administered the five SBCMCITs to 92 undergraduate students of English she obtained the results presented in Table 2. As can be seen, the verb and semantic domain SBCMCITs are the most and least reliable among the versions, i.e., .92 and .64, respectively. Since the reliability coefficient of the semantic domain SBCMCIT is .82 in the present study, the low reliability coefficient obtained by Gholami can be attributed to her small sample and the test's being the most difficult among the SBCMCITs as reflected in its mean, i.e., 20.3.

TABLE 2

DESCRIPTIVE STATISTICS AND CORRELATIONS AMONG THE FIVE VERSIONS OF THE SBCMCIT

\begin{tabular}{|l|l|l|l|l|l|l|l|l|}
\hline SBCMCITs & $\begin{array}{l}\text { \# of } \\
\text { items }\end{array}$ & Mean & SD & Alpha & TOEFL & Structure & $\begin{array}{l}\text { Written } \\
\text { expressions }\end{array}$ & Reading \\
\hline Adjective & 60 & 21.2 & 9.1 & .87 & $.551^{*}$ & $.571^{*}$ & .265 \\
\hline Adverb & 60 & 24.7 & 10.7 & .90 & $.700^{* *}$ & $.504^{*}$ & $.607 *$ \\
\hline Noun & 60 & 24.2 & 9.6 & .87 & .191 & .125 & $.633^{* *}$ & .049 \\
\hline Verb & 60 & 22.0 & 12.1 & .92 & .193 & -.133 & .283 & .256 \\
\hline Semantic domain & 60 & 20.3 & 5.8 & .64 & $.841^{* *}$ & $.559^{*}$ & $.766^{* *}$ \\
\hline
\end{tabular}

As it is also shown in Table 2, the adverb SBCMCIT is the only test which correlated significantly with the TOEFL $(0.70, \mathrm{p}<.01)$ and its structure $(0.50, \mathrm{p}<.05)$, written expression $(0.63, \mathrm{p}<.01)$ and reading $(0.63, \mathrm{p}<.01)$. However, the semantic domain SBCMCIT showed the highest significant correlations not only with the TOEFL $(0.84, \mathrm{p}<.01)$ but 
also with its structure $(0.56, \mathrm{p}<.05)$, written expression $(0.77, \mathrm{p}<.01)$ and reading $(0.74, \mathrm{p}<.01)$. Due to these highly significant correlations the semantic domain SBCMCIT was employed in the present study to find out whether the participants' cognitive styles will bear any significant relationship with their performance on semantic domain SBCMCIT.

\section{Procedure}

After coordinating with the authorities of some universities and colleges and receiving their instructors' verbal approval, the GEFT and the semantic domain SBCMCIT were administered on two different occasions with an interval of one and/or two weeks. One of the researchers was always present at testing sessions and answered whatever questions the participants raised in Persian. The tests were held under standard conditions.

\section{Data Analysis}

Following Khodadady (2008) all the schemata comprising "why don't we just kiss and make up" (Dugatkin, 2005) were parsed and codified according to their domains, genera, species, types and tokens in order to determine their frequency and percentage. The $p$-value, i.e., the number of correct answers divided by the total number of responses, and the point biserial correlation coefficients $\left(\mathrm{r}_{\mathrm{pbi}}\right)$ of items comprising the semantic domain SBCMCIT were estimated to specify its well functioning items and establish its adjective, adverb, noun and verb subtests. For correlating the SBCMCIT and its subtests with GEFT, the scores obtained on the former were changed into standardized values by employing the Descriptives command of the SPSS and saving the standardized values as variables. This function helped change all the raw scores into $\mathrm{Z}$ scores. By employing the $\mathrm{Z}$ scores, the participants who scored -1 and below, +1 and higher, and those falling between -1 and +1 on the semantic domain SBCMCIT were classified as low, high and middle proficiency test takers. One way ANOVA analysis was also utilized to find out whether the mean scores on the GEFT and semantic domain SBCMCIT and its subtests differed significantly. All the estimates and tests were conducted via SPSS version 19 to test the following five hypotheses.

H1. The FD and FI test takers will perform significantly differently on the semantic domain SBCMCIT and its subtests.

H2. The GEFT, semantic domain SBCMCIT and its subtests will correlate significantly with each other.

H3. The correlations of FI test takers' scores on the SBCMCITs and its subtests will be significant and higher than those of the FDs.

\section{RESUlTS AND DiSCUSSION}

Table 3 presents the schema domains, genera, tokens and their types. As can be seen, 1715 schema tokens or words constitute the entire text upon which the SBCMCIT is developed. This statistics is not, however, helpful in developing a test. The syntactic conjunction and, for example, has a token of 40, i.e., it has been used 40 times in the text. Similarly, the semantic noun animal has a token of six. Many scholars relate the token of words to their difficulty level, i.e., the less frequent a given word, the more difficult it is to be learned (e.g., Fountain \& Nation, 2000). In other words, selecting items on the basis of tokens will result in developing several items on the same schema and thus render them too easy.

TABLE 3

SCHEMA DOMAINS, GENERA AND TOKENS AND TYPES COMPRISING THE TEXT OF SBCMCIT

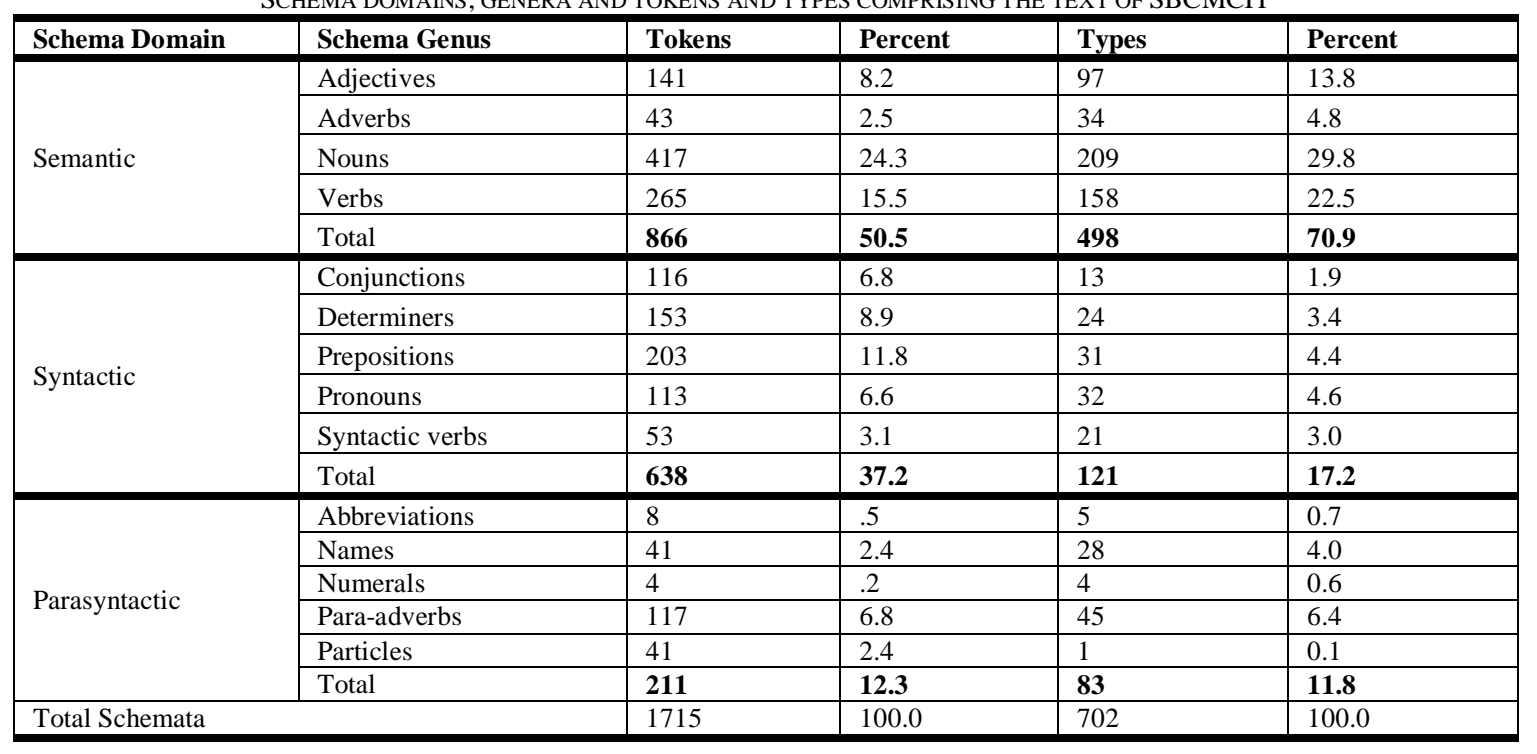


One of the greatest contributions of schema theory to language testing is its dependence on schema types rather than tokens. It requires tabulating and choosing the least frequent types on the basis of the percentage with which they constitute the text under comprehension. As can be seen in Table 3, 702 schema types constitute the text "why don't we just kiss and make up" (Dugatkin, 2005) out of which 498 (70.9\%) are semantic in nature. This means that whatever messages are conveyed in the text, they lie in these 498 semantic schemata and they must, therefore, form seventy one percent of the test if not one hundred.

Table 4 presents the descriptive statistics of the semantic domain SBCMCIT and its subtests developed on adjective, adverb, noun and verb schemata as well as GEFT. As can be seen, the percentage of item types in the former test follows the percentage of semantic schema types comprising the text. The percentage of noun-based items (40\%) is, for example, the largest as noun schemata form the largest percentage (42\%) of semantic schemata used in the text, i.e., 209 $\div$ 498. The very unique feature of semantic domain SBCMCITs in accommodating a representative percentage of adjective, adverb, noun and verb schema types in its development has made it a very reliable test $(\alpha=.82)$.

TABLE 4

DESCRIPTIVE STATISTICS OF THE SEMANTIC DOMAIN SBCMCIT, ITS SUBTESTS AND GEFT

\begin{tabular}{|l|c|c|c|c|c|c|}
\hline SBCMCITs & N of items & Mean & Std. Deviation & Mean p-value & Mean $\mathbf{r}_{\text {pbi }}$ & Alpha \\
\hline Adjective & $14(23 \%)$ & 7.16 & 2.298 & .51 & .27 \\
\hline Adverb & $7(12 \%)$ & 4.22 & 1.414 & .60 & .40 \\
\hline Noun & $24(40 \%)$ & 11.66 & 3.426 & .51 & .29 & .28 \\
\hline Verb & $15(25 \%)$ & 6.91 & 2.830 & .46 & .39 & .60 \\
\hline Semantic domain & 60 & 30.35 & 8.350 & .51 & .29 & .82 \\
\hline GEFT & 18 & 9.60 & 4.580 & .53 & .54 \\
\hline
\end{tabular}

Table 5 presents the FD and FI group statistics on the adjective, adverb, noun, verb and semantic domain SBCMCIT as well as the result of one way ANOVA analysis. (The table belonging to ANOVA analysis has not been given to save space.). As can be seen, the mean scores of FI test takers are significantly higher than those of FD's not only on the semantic domain SBCMCITs but also on its subtests. These results confirm the first hypothesis that the FD and FI test takers will perform significantly differently semantic domain SBCMCITs and its subtests.

TABLE 5

DESCRIPTIVE STATISTICS OF FD AND FI TEST TAKERS' SCORES ON THE SBCMCITS AND THEIR ANOVA ANALYSIS

\begin{tabular}{|c|c|c|c|c|c|c|}
\hline Genus & Field & $\mathbf{N}$ & Mean & Std. Deviation & $\begin{array}{l}\text { Std. Error } \\
\text { Mean }\end{array}$ & ANOVA \\
\hline Adjective & Dependent & 149 & 6.52 & 2.321 & .190 & $\mathrm{~F}=31.372, \mathrm{df}=1, \mathrm{p}<.0001$ \\
\hline \multirow{2}{*}{ Adverb } & Dependent & 149 & 3.91 & 1.454 & .119 & \multirow{2}{*}{$\mathrm{F}=19.345, \mathrm{df}=1, \mathrm{p}<.0001$} \\
\hline & Independent & 104 & 4.67 & 1.226 & .120 & \\
\hline Nouns & Dependent & 149 & 10.59 & 3.128 & .256 & $\mathrm{~F}=41.26, \mathrm{df}=1, \mathrm{p}<.0001$ \\
\hline Verbs & Independent & 104 & 8.27 & 2.600 & .255 & $\mathrm{~F}=48.828, \mathrm{df}=1, \mathrm{p}<.0001$ \\
\hline \multirow{2}{*}{ Semantic domain } & Dependent & 149 & 27.34 & 7.853 & .643 & \multirow{2}{*}{$\mathrm{F}=57.669, \mathrm{df}=1, \mathrm{p}<.0001$} \\
\hline & Independent & 104 & 34.66 & 7.079 & .694 & \\
\hline
\end{tabular}

Table 6 presents the correlations among the GEFT, the semantic domain SBCMCITs and its subtests. As can be seen, the GEFT correlates significantly with the SBCMCITs developed on semantic genera and domain and thus confirm the second hypothesis that the GEFT, semantic domain SBCMCIT and its subtests will correlate significantly with each other. As can be seen, the correlation coefficient of the GEFT with the semantic domain SBCMCIT is 0.44 (p <.01), indicating that about $19 \%$ percent of test takers performance on the latter can be explained by the former. And most interestingly, the verb SBCMCIT shows the second highest correlation with the GEFT, i.e., .40 (p <.01), while its constituting items are fewer than the noun SBCMCIT, i.e., 15 and 24, respectively, revealing a previously unknown process in language learning, i.e., test takers employ their cognitive styles to answer verb items more than the nouns. In other words verb schemata are more context-bound or field dependent than noun schemata.

TABLE 6

CORRELATIONS AMONG THE GEFT, SEMANTIC DOMAIN SBCMCITS AND ITS SUBTESTS

\begin{tabular}{|l|l|l|l|l|l|l|}
\hline Style & $\mathbf{N}$ & Adjective & Adverb & Noun & Verb & Semantic domain \\
\hline Dependent & 148 & $.213^{* *}$ & .157 & $.191^{*}$ & $.230^{* * *}$ & $.247^{* *}$ \\
\hline Independent & 105 & -.163 & -.082 & -.185 & $-.208^{*}$ & $-.223^{*}$ \\
\hline GEFT & 253 & $.351^{* *}$ & $.291^{* *}$ & $.377^{* *}$ & $.401^{* *}$ & $.441^{* *}$ \\
\hline
\end{tabular}

As it can also be seen in Table 6 , the adjective $(\mathrm{r}=.21, \mathrm{p}<.01)$, noun $(\mathrm{r}=.19, \mathrm{p}<.05)$, verb $(\mathrm{r}=.23, \mathrm{p}<.01)$, and semantic domain SBCMCITs $(\mathrm{r}=.25, \mathrm{p}<.01)$ show significant relationships with the FD test takers' performance on the GEFT 
whereas only the verb and semantic domain SBCMCIT of the FI test takers show negatively significant correlations with the GEFT, i.e., $-.21(\mathrm{p}<.05)$ and $-.22(\mathrm{p}<.05)$, respectively. These results disconfirm the third hypothesis that the correlations of FI test takers' scores on the SBCMCITs will be significant and higher than those of the FDs. Although the mean scores of FI test takers were significantly higher than those of FDs, the latter's cognitive styles show unexpectedly higher and more significant relationships with the semantic domain SBCMCIT and its subtests, implying that their level of language proficiency was higher than those of the FIs.

In order to explain the negative relationship between the GEFT and the FI test takers' performance on the verb and semantic domain SBCMCITs, all test takers were divided into three low, middle and high proficiency groups on the basis of their z-scores on the semantic domain SBCMCIT. Table 7 presents the mean scores of the three proficiency groups on the SBCMCIT. It also shows the mean score of these test takers on the GEFT. As can be seen, the mean score of high proficiency test takers, i.e., 43.2, is higher than the middle, i.e., 30.9, and the low, i.e., 19.5, on the SBCMCIT. The one way ANOVA test revealed that the mean scores of low, middle and high proficiency groups were significantly different $(\mathrm{F}=398.185, \mathrm{df}=2, \mathrm{p}<.0001)$.

TABLE 7

THE MEAN SCORES OF LOW, MIDDLE AND HIGH PROFICIENCY PARTICIPANTS ON THE GEFT AND SBCMCIT

\begin{tabular}{|l|l|l|l|l|l|l|l|}
\hline \multirow{2}{*}{ Proficiency } & \multirow{2}{*}{$\mathrm{N}$} & Mean & Std. Deviation & \multicolumn{2}{l|}{ Std. Error } \\
\cline { 3 - 9 } & & GEFT & SBCMCIT & GEFT & SBCMCIT & GEFT \\
\hline Low & 56 & 6.29 & 19.48 & 4.207 & 2.157 & .562 & .288 \\
\hline Middle & 156 & 10.12 & 30.89 & 4.319 & 4.682 & .346 & .375 \\
\hline High & 41 & 12.17 & 43.15 & 3.514 & 3.692 & .549 & .577 \\
\hline Total & 253 & 9.60 & 30.35 & 4.580 & 8.350 & .288 & .525 \\
\hline
\end{tabular}

As it can also be seen in Table 7, the mean scores obtained by low, middle and high proficiency groups on the GEFT are different. The one way ANOVA test revealed that the difference is significant at the highest level possible, i.e. $\mathrm{F}=26.634, \mathrm{df}=2, \mathrm{p}<.0001$, among the three groups of proficiency. In order to be sure that the significant difference existed among each and all of the three different proficiency groups, not just the three as a whole, the Scheffe post hoc test presented in Table 8 was run on the mean scores on both the SBCMCIT and GEFT. As can be seen, the mean scores of the three groups were significantly different from each other on both cognitive styles and language proficiency tests.

TABLE 8

MULTIPLE COMPARISONS OF THE SBCMCITS AND GEFT CONDUCTED VIA SCHEFFE POST HOC TEST

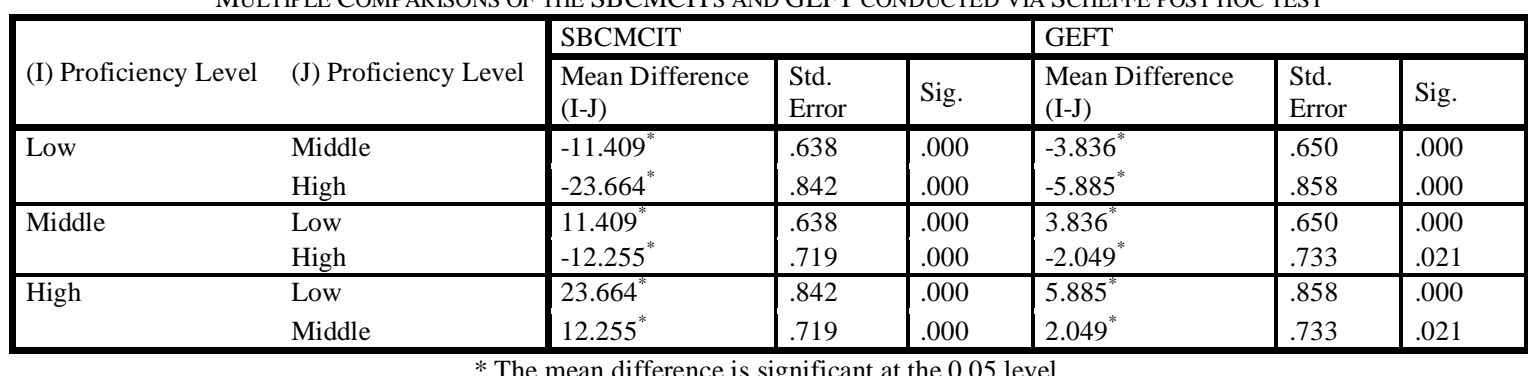

The results presented in Table 7 also indicate that the classification of participants into FD and FI on the basis of their raw scores on the GEFT is misleading because middle proficiency test takers employ FD and FI cognitive styles as compensatory strategies to reach the desired proficiency level. It is, therefore, suggested that the exploration of the relationship between the GEFT and an ability measure such as the SBCMCIT must be based on the mean scores obtained by predefined groups rather than raw scores on the GEFT. The mean of the middle proficiency participants on the GEFT, for example, is 10.12. However, a look at their raw scores on the GEFT shows that they range from 1 to 17. In other words, determining the relationship between cognitive styles and abilities such as language proficiency must be based on the mean GEFT in relation to a defined level of ability, e.g., low, middle and high, rather than the ability as a whole.

Table 9 presents the correlation coefficients obtained among the GEFT, semantic domain SBCMCIT and its subtests. As can be seen, all test takers' scores on the GEFT show significant correlations not only with semantic domain SBCMCIT but also with its four subtests. The significant correlations, however, disappear when proficiency levels are considered separately, implying that it is the language proficiency level measured by the SBCMCITs which entails the employment of certain cognitive styles rather than vice versa. 
TABLE 9

CORRELATIONS OBTAINED AMONG THE GEFT, SEMANTIC DOMAIN SBCMCIT AND ITS SUBTESTS

\begin{tabular}{|l|l|l|l|l|l|}
\hline Proficiency groups & Adjective & Adverb & Noun & Verb & Semantic \\
\hline Low Proficiency & .198 & -.043 & .000 & .042 & .199 \\
\hline Middle Proficiency & .136 & .150 & $.194^{*}$ & $.236^{* *}$ & $.280^{* *}$ \\
\hline High Proficiency & -.235 & -.125 & -.164 & -.027 & -.264 \\
\hline All Proficiencies & $.351^{* *}$ & $.291^{* *}$ & $.377^{* *}$ & $.401^{* *}$ & $.441^{* *}$ \\
\hline
\end{tabular}

Since low proficiency learners have little knowledge of the semantic schemata to comprehend the passage, their cognitive styles fails to play any significant role on the SBCMCITs. Similarly, the highly proficient learners depend solely on their schema-based knowledge to cope with the reading comprehension task. The middle proficiency learners are the only group who employ their cognitive styles to compensate for their missing knowledge in answering verb and noun SBCMCITs in particular and the semantic domain SBCMCIT in general. In other words, the application of both FD and FI cognitive styles by middle proficiency learners of English explains approximately eight percent of their performance on the semantic domain SBCMICT. Since the mean score of the middle proficiency group is 10.12 on the GEFT, it indicates that half of the test takers in this group employ their field dependency to find the keyed response on the SBCMCIT while the other half utilize their field independency to fulfill the same function.

\section{CONCLUSION}

A cloze multiple choice item test (MCIT) developed on the adjectives, adverbs, nouns and verbs constituting the semantic domain of an unmodified and authentic text was administered to 253 undergraduate and graduate students of English to determine whether there is a significant relationship between their cognitive styles and language proficiency. In contrast to traditional cloze MCITs whose four choices are constructed intuitively, the test employed in this study consisted of items whose three choices had syntactic, semantic and discoursal relationships with the keyed response and it was, therefore, referred to as schema-based cloze multiple choice item test (SBCMCIT). The choices of the SBCMCITs are called competitives in the literature in order to differentiate them from distracters as their traditional counterparts. The results showed that the SBCMICT is a fair measure of language proficiency because the performance of neither low nor high proficiency test takes' on the SBCMCIT showed any significant relationships with the GEFT as a widely employed measure of field dependency (FD) and independency (FI) cognitive styles.

Since choosing the keyed response from among the three syntactically, semantically and discoursely related competitives on the SBCMCIT does require focusing not only on the competitives themselves, i.e., field independence, but also on the context in which the keyed response appears, i.e., field dependency, the performance of low and high proficiency test takers on the SBCMCIT and GEFT do not show any significant relationships with each other. Both FD and FI middle proficiency test takers, however, employ their cognitive styles to compensate for their lack of language proficiency required to comprehend the reading passage and thus their scores on the noun, verb and semantic domain SBCMCITs and GEFT correlate significantly with each other. The findings of this study, therefore, show that the SBCMICTs are not only valid and reliable but also fair measures of language proficiency because they do not favor any specific cognitive style over another. A replication study is, however, required to find out whether similar results will be obtained if the SBCMCITs and GEFT are administered to a similar but larger sample and/or the proficiency level of the test takers is determined by another test such as the TOEFL and IELTS before the SBCMCITs are administered.

\section{REFERENCES}

[1] Allinson, C., \& Hayes, J. (1996). The Cognitive Style Index. Journal of Management Studies, 33, 119-35.

[2] Dornyei, Z. (2005). The psychology of the language learner. US: Lawrence Erlbaum Associates.

[3] Duagtkin, L. (May 7, 2005) Why don't we just kiss and make up? New scientist, 2498, p.35, Retrieved from http://www.newscientist.com/channel/life/mg186249810300.

[4] Fountain, R. L., \& Nation, P. (2000). A vocabulary-based graded dictation test. RELC Journal 31, 29-44.

[5] Gholami, M. (2006). The effect of content schema type on Iranian test takers' performance. Unpublished MA thesis, Ferdowsi University of Mashhad, Iran.

[6] Goldstein, K., \& Blackman, S. (1978). Cognitive style. New York: Wiley.

[7] Gregorc, A. F. (1982). An adult's guide to style. Maynard, MA: Gabriel Systems.

[8] Hayes, J., \& Allinson, C. W. (1998). Cognitive style and the theory and practice of individual and collective learning in organizations. Human Relations, 51, 847-871.

[9] Hudson, L. (1966). Contrary Imaginations. London, Penguin.

[10] Jarvis, M. (2005). The psychology of effective learning and teaching. UK: Nelson Thrones Ltd.

[11] Kahtz, A.W., \& Kling, G.J. (1999). Field-dependent and field-independent conceptualization of various instructional methods with an emphasis on CAI: A qualitative analysis. Educational Psychology, 19, 413-428.

[12] Keefe, J. W. (1979). Learning styles: An overview. In Student learning styles: Diagnosing and prescribing programs (pp. 1-17). Reston, VA: National Association of Secondary School Principals. 
[13] Khodadady, E. (1997). Schemata theory and multiple choice item tests measuring reading comprehension. Unpublished PhD thesis, the University of Western Australia.

[14] Khodadady, E. (1999a). Multiple-choice items in testing: Practice and theory. Tehran: Rahnama.

[15] Khodadady, E. (1999b). Reading media texts: Iran-America relations. Sanandaj: Kurdistan University Press.

[16] Khodadady, E. (2008). Schema-based textual analysis of domain-controlled authentic texts. Iranian Journal of Language Studies (IJLS), 2(4), 431-448.

[17] Khodadady, E., \& Herriman, M. (2000). Schemata theory and selected response item tests: from theory to practice. In A. J. Kunnan (Ed.), Fairness and validation on language assessment (pp. 201-222). Cambridge: CUP.

[18] Luk, S. C. (1998). The relationship between cognitive style and academic achievement. British Journal of Educational Technology, 29(2), 137-147.

[19] Paivio, A. (1971). Imagery and verbal processes. New York: Holt, Rinehart \& Winston.

[20] Paivio, A. (1986). Mental Representations: A Dual Coding Approach. New York, NY: Oxford University Press.

[21] Pask, G. (1976). Conversation theory: Applications in education and epistemology. Amsterdam: Elsevier.

[22] Pask, G. (1988). 'Learning strategies, teaching strategies, and conceptual or learning style.” In R. R. Schmeck (Ed.), Learning Strategies and Learning Styles (Ch. 4, 83-100). New York: Plenum Press.

[23] Salmani-Nodoushan, M. A. (2007). Is field dependence or independence a predictor of EFL reading performance? TESL Canada Journal, 24(2), 82-108.

[24] Witkin, H.A. (1974). Psychological differentiation: studies of development. New York: Wiley.

[25] Witkin, H.A., Goodenough, D. R. (1981). Cognitive Styles: Essence and Origins. Field Dependence and Field Independence. New York: International Universities Press.

[26] Witkin, H.A., Oltman, P.K., Raskin, E., \& Karp, S.A. (1971). A Manual for the Group Embedded Figures Test. Palo Alto, CA: Consulting Psychologists Press.

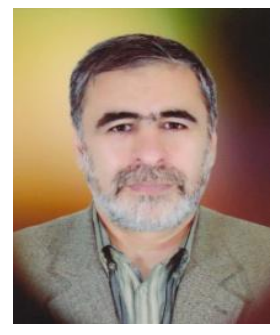

Ebrahim Khodadady was born in Iran in 1958. He obtained his $\mathrm{PhD}$ in Applied Linguistics from the University of Western Australia in 1998. He holds TESL Ontario and Canadian Language Benchmarks Placement Test (CLPBPT) certificates and has taught English as a first, second and foreign language to high school and university students in Australia, Canada and Iran.

$\mathrm{He}$ is currently an academic member of English Language and Literature Department at Ferdowsi University of Mashhad, Iran. He was invited as a VIP by Brock University in Canada in 2004 and served as the Associate Director of Assessment Center at George Brown College in Toronto for almost a year. His published books are Multiple-Choice Items in Testing: Practice and Theory (Tehran, Rahnama, 1999), Reading Media Texts: Iran-America Relations (Sanandaj, Kurdistan University, 1999) and English Language Proficiency Course: First Steps (Sanandaj, Kurdistan University, 2001). His main research interests are Testing, Language Learning and Teaching.

Dr. Khodadady is currently a member of TESL Ontario and European Society for Translation Studies. He is on the editorial board of Ferdowsi Review: An Iranian Journal of TESL, Literature and Translation Studies and has reviewed some research papers for Iranian Journal of Applied Linguistics and TESL Canada Journal as a guest reviewer.

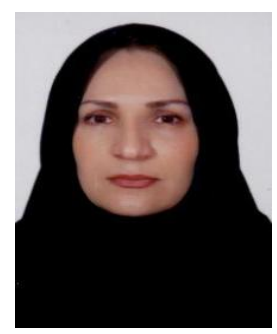

Azar Hosseini Fatemi was born in Iran in 1951.She got her BA in English Language and Literature from FUM, Iran: Her MA in Teaching English from New Mexico State University, USA, in 1980; and her PhD. from Punjab University, India.

She is currently an academic member of English Language \& Literature Department at Ferdowsi University of Mashhad, Iran. She has 27 years of teaching experience eat both graduate and under-graduate levels. So far she has supervised more than 40 MA theses. She has also been involved in a few research projects. She was the head of the department for four years (2001-2005).

She is the executive manager and a member of editorial board of "Ferdowsi Review, An Iranian Journal of TESOL, Literature and Translation Studies".

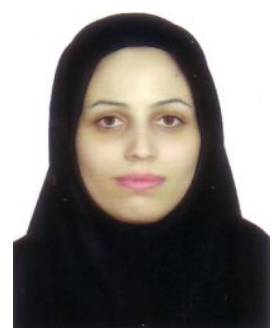

Saba Etminan was born in 1985 in Iran. She holds an MA in Teaching English from Ferdowsi University of Mashhad. She has been teaching general English in private institutes for six years. Currently she is a teacher at Aryan English College in Mashhad. Her research interests are teaching and testing. 